the United States and Canada. Already its hands are full, for in addition to a heavy programme of longrange research, it is the centre at which agricultural cadets receive their training for work in the agricultural departments right through the tropical Colonies of the British Empire. The College also trains men for agricultural work in the West Indian area. If it is to be charged with a number of specific West Indian problems in addition, it will need a good deal more financial support, and will have to be expanded. It is undoubtedly the best place at which to carry out the contemplated researches, and, given adequate funds and the necessary increase in staff, there is no reason to doubt that it will fulfil its task.

The West Indies appear to be on the verge of great new developments. The traditional economic system which depended on the production of export crops and the import of food needs modification. Efforts must be made to render these Colonies far more selfsupporting in their food requirements than has been the case in the past, for it is believed that a country which is self-supporting in food is far better able to tide over the periodic trade depressions which inevitably occur, since during such periods the export crops may have to be sold at prices far below cost of production or difficulty may even be felt in disposing of them at all. In either case, there is little enough money available to purchase even the bare necessities of life. So, the next few years may see a radical change in the West Indies in the direction of a more rational system of agriculture, having as its main object the better utilization of the land and the preservation of the all-important soil. The policy of settling people on small holdings will be accelerated with the main object of making these Colonies more self-supporting as regards food. In order to effect this, some of the estates which are redundant, or cannot be worked profitably as plantations under existing economic conditions, will have to be taken over and settled with small holders. This does not necessarily mean that the plantation system as a whole with disappear. Many of those which are favourably situated, such as the sugar estates in the larger islands, must continue, and should benefit because the change should result in a more assured supply of labour from a settled peasantry. In fact, a combination of the two systems, each lending support to the other and with interlocking interests, would seem to be the happiest augury for the future.

\section{CARL VON LINDE A Pioneer of 'Deep' Refrigeration}

\section{BY J. H. AWBERY}

National Fhysical Laboratory

ARL VON LINDE is probably known to most scientific workers as the designer of a liquid-air machine, and nothing else. He contributed, however, to ordinary refrigeration as well, and still more to the problems of gas separation which are now becoming of such technical importance. Thus it is fitting, in this year which sees the centenary of his birth-he was born on June 11, 1842-to survey his work and to realize the debt which we owe to him.

It was in 1876, when he was thirty-four years of age and professor of thermodynamics at Munich, that Linde took out his patent for an ammonia refrigerating machine. Before this, machines using ether had been used (they are now obsolete), as well as bulky and inefficient cold-air machines; but Linde had the scientific knowledge to calculate the thermodynamic efficiency attainable with different media, and the technical skill to design the plant well-so much so that Ewing, writing in 1908, was able to say : "The design of the Linde machine has been carried out with conspicuous care, and it owes much of its great success to excellence in mechanical detail". From the time of its introduction until recent years, the ammonia machine has been the most widely used refrigerating plant for all purposes except marine work, where carbon dioxide (which also was introduced by Linde, though independently by others) was preferred for various reasons. In recent years, the advent of the turbo-compressor has led to the use of organic refrigerants for air-conditioning work. The wide demand for small domestic plants has also been associated with the use of organic liquids, so that ammonia, though still widely used, is less dominant than formerly.

When he began to work on the production of liquid air, Linde had a clear idea of using it to produce oxygen by fractional distillation, and probably saw this as more important than the attainment of very low temperatures. At the time, air had already been liquefied by various investigators using a number of methods. Linde, in 1893, used a process not unlike that of the ordinary refrigerating plant, but with a heat interchanger to make the cooling cumulative. The air to be liquefied is compressed to a high pressure, cooled by circulating water, and then expanded through a throttle valve. (It is at this point that the process used by Claude differs. In Claude's arrangement, the gas expands in a cylinder and is made to do work so that the process is nearly adiabatic.) Here the temperature falls owing to the unresisted expansion. The cooled air leaving the valve then passes away up the outside of the pipe along which the air flows to the valve; thus the following air starts its expansion at a lower temperature. In this way, the air leaves the valve at continuously lower temperatures, until at last the boiling point is reached, and some of the air liquefies. From this time on, a steady state is approximately reached, in which part of the air leaving the valve flows away in the gaseous form, and may be regarded as the refrigerant, which completes its thermodynamic cycle by warming up to atmospheric temperature, while the remainder is liquefied.

The details of the process have, of course, been modified, but in principle Linde's first apparatus has been closely followed in subsequent design, and has been the basis, not only of liquid-air plants on a large scale, but also of plants for the liquefaction of hydrogen.

One of the two main deviations from the simple process outlined above consists in avoiding the waste which results from the expansion of all the air from high pressure to atmospheric. Actually, it is only that part of the air which is to be drawn off that need be lowered to atmospheric pressure. The remainder, which acts as the refrigerant, can be kept at a much higher pressure, thus greatly reducing the work of compression. To this end, the air at about 200 atmospheres is expanded to 40 atmospheres, and only that part which is to be drawn off is afterwards expanded to atmospheric pressure. It is found in practice that this increases the amount of liquid air obtainable for a given input of energy by about 10 per cent. 
The other economy is to cool the air, before compression, by means of a subsidiary (ammonia) refrigerating plant. When the two modifications are used together, the efficiency is raised from about 0.1 gallon per $\mathrm{kwh}$. to $0 \cdot 3$ gallon per $\mathrm{kwh}$.

As mentioned above, Linde undertook the design of a liquid-air plant originally with the idea of using it to extract oxygen from the air, as an improvement on the chemical method then in use. His first really successful apparatus was described in 1902, and utilized the principle of the familiar rectifying column. This depends for its action on the facts that liquid and vapour in equilibrium with each other have different compositions, and that the boiling point of oxygen is higher than that of nitrogen. Thus a liquid with 20 per cent nitrogen and 80 per cent oxygen is in equilibrium with a vapour containing 52 per cent nitrogen and 48 per cent oxygen, while liquid with 80 per cent nitrogen and 20 per cent oxygen corresponds to a vapour with 95 per cent nitrogen and only 5 per cent oxygen.

In a simple rectifier for the production of oxygen, the liquid air, at a temperature just below its boiling point, enters the top of the column, consisting of a chamber stacked with glass balls, over which it trickles to the bottom. The liquid in the column meets a rising stream of oxygen, which is itself cooled and condensed, thereby giving up heat which evaporates nitrogen from the down-flowing liquid. The latter thus becomes progressively richer in oxygen, until at the bottom it consists of nearly pure oxygen. Arrangements are made to draw off the gas from the liquid which collects at the bottom. In its path, it is used to cool the incoming air, and similarly the nitrogen which escapes from the top of the column is made to act as a cooling medium before it finally escapes. By the nature of the process, if pure oxygen is required, the escaping nitrogen is far from pure; conversely, if the rectifier is operated so as to obtain pure nitrogen, then the oxygen is impure. To obtain both elements pure would require multiple rectification, in which the products from both ends were separately redistilled, and it is not at present commercial practice to make both gases in one plant.

It should be noted that the operation of a rectifying column so as to produce pure nitrogen involves appreciable modification. Instead of collecting the desired product as a liquid at the bottom, and allowing some to evaporate, it is then necessary to collect the gas at the top and to condense some of it to provide a downflow of the liquid. The device suitable for this purpose was introduced by Linde some eight years after his first rectifier, and is described as the Linde double-column rectifier.

In the early days of this subject, the only product of commercial importance was oxygen, which is now used (for example, in welding) on an enormous scale. In the last twenty years, however, the demand for nitrogen has become equally important, in view of its use in synthesizing ammonia. When it is required for this purpose, the plant which liquefies and rectifies the air is invariably on the site of the synthetic ammonia works, and the nitrogen merely flows along a pipe line from the rectifier to the point where it is used. Nitrogen of purity $99 \cdot 96$ per cent is now manufactured commercially, without the necessity for any chemical treatment.

This development would have astonished Linde, to whom the nitrogen was not only a troublesome impurity, but the more so on account of its being present to the extent of four fifths of the whole raw material.
His astonishment at the rise of nitrogen to an importance such that the two gases are now prepared in roughly equal quantities, would be small compared with his amazement if he could learn that some air is now liquefied for the sole purpose of extracting argon from it, and that there is every likelihood of a thriving industry growing up to extract krypton and xenon-gases which are present in the atmosphere to the extent of $1 \cdot 1$ and 0.08 parts in a million by volume.

Up to the present, the demand for argon arises solely from the needs of the gas-filled lamp, where its high molecular weight makes it of value in preventing the evaporation of the filament, and thus enables the latter to run at a high temperature and a correspondingly high luminous efficiency. Although the gasfilled lamp was only introduced about twenty years ago, its importance may be gauged from the fact that some thousand million such lamps are now made annually.

To separate argon from air, the latter is first fractionated into two components, an argon-oxygen mixture free from nitrogen and an impure nitrogen, which is rejected. The mixture of argon and oxygen is then rectified, by apparatus of the same type as that used in simple rectification; the argon so produced contains the residual nitrogen from the oxygenargon mixture, the oxygen being practically free from nitrogen and containing about 0.2 per cent argon. The oxygen, of course, is not wasted; it is in fact an economic necessity to obtain a second product when the necessary large volumes of air are being treated to extract the 1 per cent argon which they contain.

Helium and neon have boiling points far below those of argon, oxygen and nitrogen. Hence they remain in the gaseous form, and accumulate at the top of the separating column. It is in some works found profitable to collect these gases from time to time, since neon is, or was until the black-out, in demand as a filling for the gas discharge tubes of striking red colour widely used for advertising purposes.

It is clear from what has been said above that Linde was one of those pioneers whose work was so well done that it could bear extension in many directions: for many of the later developments, carried out since his death, have retained his methods with only minor modifications.

\section{OBITUARIES}

\section{Sir Joseph Larmor, F.R.S.}

JosePH LARMor was born at Magheragall, Co. Antrim, on July 11, 1857. In his schooldays at the Royal Belfast Academical Institution, he is described as a "thin and delicate black-haired boy of most precocious ability both in mathematics and classics". He gained a scholarship at Queen's College, Belfast, where he graduated with the highest honours. From there he proceeded to St. John's College, Cambridge. A severe illness made it necessary for him to lose a year; but he took the Mathematical Tripos in 1880 and came out Senior Wrangler, J. J. Thomson being second. Larmor was at once appointed professor of natural philosophy in Queen's College, Galway. He was there during 1880-85, and then returned to St. John's College as lecturer. In 1903 the Lucasian 